\title{
Abordagem da família convivendo com HIV/AIDS na atenção primária pelo residente em medicina de família e comunidade
}

\author{
José de Assis e Souza Júnior ${ }_{1}^{1 \star}$ Garcia Alejandro V. Figueroa, ${ }_{1}^{1}$ Nelson Robson M. de Souza ${ }^{2}$
}

\begin{abstract}
Resumo
O presente relato de caso apresentará as técnicas (fundadas na abordagem humanista) aprendidas durante o Programa de Residência Rédica em Medicina de Família e Comunidade que ajudaram a compreender e trabalhar com a família estudada. Essas tecnologias foram utilizadas no aconselhamento, diagnóstico, tratamento e acompanhamento na atenção primária de uma família com agravos de longa data. Dentre eles citamos o uso abusivo de drogas, a violência psíquica, sexual e física entre eles próprios (e de fora), assim como agravos novos, como o diagnóstico de HIV dos pais, os preconceitos que acompanham a doença, as dificuldades do tratamento e o estresse do adoecimento.
\end{abstract}

Descritores: Atenção primária à saúde; HIV; Humanização da assistência.

\section{Abstract \\ Approach to the family living with HIV in the primary health care by the family and community medicine resident}

The case report presents techniques (based on a humanistic approach) learned during the Family and Community Medical Residence Program, which helped to understand and work with the studied family. These techniques were used in counseling, diagnosis, treatment and follow-up in primary care of a family with long-term conditions. Among them, we can mention drug abuse; psychological, sexual or physical violence that occurs internally and externally to the family. Also, new conditions such as parents' HIV diagnosis, prejudices against the disease, difficulties of treatment and sickness-induced stress.

Keywords: Primary health care; HIV; Humanization of assistance.
1. Programa de Residência Médica em Medicina de Família e Comunidade. Hospital Universitário Pedro Ernesto. Universidade do Estado do Rio de Janeiro. Rio de Janeiro, RJ, Brasil.

2. Departamento de Medicina Integral, Familiar e Comunitária. Faculdade de Ciências Médicas. Universidade do Estado do Rio de Janeiro. Rio de Janeiro, RJ, Brasil.

*Endereço para correspondência:

Av. Professor Manuel de Abreu, 444, 2 andar

Rio de Janeiro, RJ. CEP: 20550-170.

E-mail: assismedicina@yahoo.com.br

Revista HUPE, Rio de Janeiro, 2016;15(3):294-299

doi: $10.12957 /$ rhupe.2016.30645

Recebido em 25/07/2016. Aprovado em 10/04/2017.

\section{Resumen}

Abordaje de la familia que convive con HIV/AIDS en la atención primaria del residente en medicina de familia y comunidad

El relato de caso presenta técnicas (fundadas en el abordaje humanista) aprendidas durante el Programa de Residencia Médica en Medicina de Familia y Comunidad, que ayudaron a comprender y a trabajar con la familia investigada. Estas técnicas fueron utilizadas en la orientación médica, diagnóstico, tratamiento y acompañamiento en atención primaria de una familia con afecciones de muchos años. Entre ellas, podemos mencionar el abuso de drogas y la violencia psíquica, sexual y física que ocurren al interior y exterior de la familia. Además de nuevas afecciones, tales como el diagnóstico de HIV de los padres, los afecciones que acompañan a esta enfermedad, las dificultades del tratamiento y el estrés por encontrarse enfermo.

Palabras clave: Atención primaria de salud; VIH; Humanización de la atención. 


\section{Introdução}

A Política Nacional de Atenção Básica tem na Saúde da Família sua estratégia prioritária para expansão e consolidação da atenção básica. Aqui entendida como primordial, a atenção básica caracteriza-se por um conjunto de ações de saúde, no âmbito individual e coletivo, que abrange a promoção e a proteção da saúde, a prevenção de agravos, o diagnóstico, o tratamento, a reabilitação, a redução de danos e a manutenção da saúde com o objetivo de desenvolver uma atenção integral que impacte na situação de saúde e autonomia das pessoas e nos determinantes e condicionantes de saúde das coletividades. ${ }^{1}$

Nesse modelo há um território delimitado para uma equipe multiprofissional, composta por um médico, um enfermeiro, um técnico em enfermagem e 4-6 agentes comunitários de saúde (ACS) moradores do território, para o atendimento de, no máximo, 4.000 pessoas, sendo a média recomendada de 3.000 pessoas, respeitando critérios de equidade para esta definição. Recomenda-se que o número de pessoas por equipe considere o grau de vulnerabilidade das famílias daquele território, sendo que quanto maior o grau de vulnerabilidade menor deverá ser a quantidade de pacientes por equipe. ${ }^{1}$

Será relatada aqui a abordagem do caso de uma pessoa vivendo com HIV/AIDS (PVHA) e sua família, as ferramentas utilizadas no acolhimento, no enfrentamento de sua doença e nos problemas econômicos, sociais, familiares e da própria doença que apareceram nesse percurso até o amparo a ele e seus familiares nos seus últimos dias de vida, bem como a continuação do cuidado dos entes desse paciente. Esperamos passar a complexidade das necessidades dessas pessoas diante dessa doença ainda estigmatizada e com tantas nuances psicológicas, sociais e comportamentais.

\section{Objetivo}

Relatar a utilização das ferramentas tecnológicas aprendidas no Programa de Residência em Medicina de Família e Comunidade (PRMFC) e suas aplicações na prática de uma equipe da Atenção Primária à Saúde (APS) na coordenação do cuidado, no acolhimento, na longitudinalidade do cuidado e na integralidade de pessoas com doenças crônicas como o HIV.

\section{Relato de caso}

O acolhimento dessa família (Figura 1) se iniciou com o pré-natal da filha primogênita em 2013. Mo- ravam em um casebre. Recebiam os ACS para cadastramento das pessoas da casa e visitas domiciliares somente do portão (não se tinha acesso à casa).

O pai, 48 anos, ensino fundamental incompleto, trabalhador informal de um bar na comunidade, onde morava há 30 anos, em maio de 2014 procurou atendimento na Unidade Básica de Saúde (UBS) com queixas de coceira no pênis, mas sem lesão aparente. Informou que morava com a mãe de seus filhos no mesmo domicílio, mas estavam separados havia oito anos. Após aconselhamento pré-teste, foi solicitado sorologia para HIV e marcado retorno. Em junho do mesmo ano teve a confirmação do exame positivo para HIV. O pai comparece à UBS com piora do quadro geral: náuseas, hiporexia, candidíase oral, linfonodomegalia submandibular, emagrecimento e febre, "Pensei que era uma pneumonia, pois trabalho na madrugada e fumo", disse. Após esclarecimento do diagnóstico ele se abriu dizendo ter parceiras sexuais e não ter hábito de usar preservativo, conversou sobre o uso diário de cocaína e bebidas alcoólicas. Foram iniciados medicamentos profiláticos para prevenção de infecções oportunistas e solicitados exames que constam nos protocolos de cuidados das PVHA, além da busca ativa às parceiras.

Durante quase 30 dias o pai não procurou a UBS, nem o ACS do território conseguiu contato. Como uma das ferramentas tecnológicas mais efetivas para a medicina de família e comunidade (MFC), foi realizada uma visita domiciliar (VD) à casa da família em julho de 2014.

A casa, onde viviam todos, inclusive com animais e suas fezes (possuíam um cão e um gato), encontrava-se em mau estado de conservação e iluminação, mal-arejada (com único foco de luz para quatro cômodos); ambiente completamente insalubre. $O$ pai encontrava-se deitado no canto de um dos cômodos, com cobertores sujos à sua volta e um "balde sanitário" (para vômitos, fezes e urina). As filhas e a esposa não pareciam menos acuadas, dentro do outro cômodo escuro da casa que faziam de quarto separado para elas e o pequeno lactente. Diziam saber do diagnóstico do marido e ter medo de terminar como ele. Medo era o que todos sentiam naquele ambiente.

O estado geral do pai deteriorava. A esposa foi orientada quanto à importância da higiene do ambiente doméstico, dos cuidados próprios de suas filhas e neto, e a comparecer à UBS para realizar os testes de detecção de HIV. Em agosto daquele ano o pai foi internado na enfermaria de clínica médica do Hospital Universitário Pedro Ernesto (HUPE), apresentando um quadro séptico, com o diagnóstico de esporotricose 


\section{Caso clínico}

(presente em lesões de pele e no líquor). Nesse período foram realizadas visitas hospitalares a fim de compartilhar da história natural do paciente com os médicos da enfermaria do HUPE e deixar a família inteirada da situação clínica do pai.

Enquanto os cuidados do pai se voltaram para a unidade hospitalar, mãe e filhas compareceram à UBS. A mãe conta sua história familiar, do abuso de substâncias não somente dela, mas também do esposo e filhas, e do medo de ter a doença do marido (apesar de estarem separados, sofria violência sexual do esposo). Foi realizada escuta ativa de sua narrativa, diferente da história clínica tradicional que se limita ao tempo presente, não explora as relações com o futuro ou com as interpretações do passado, procura restringir o foco da escuta aos aspectos factuais surgidos a partir da doença e seus sintomas presentes na história. ${ }^{2}$ Após a realização do aconselhamento pré-teste e teste para HIV, o resultado foi positivo. Assintomática, decidimos por aguardar os resultados de carga viral e contagem de linfócitos T CD4 para definir uma conduta medicamentosa, mas com o método clínico centrado na pessoa iniciamos seu tratamento com uma política de redução de danos (cessar tabagismo, uso de drogas e fazer uso de preservativo nas relações sexuais). O familiograma e ecomapa (Figura 2) realizado em uma consulta do Ambulatório de Medicina Integral (AMI) do HUPE foram impactantes para a paciente e ajudaram no contexto da redução de danos e no sucesso do tratamento com a terapia antirretroviral (TARV).

Novamente, em agosto de 2014, outra VD foi realizada, os animais não frequentavam mais o interior da casa, suas fezes eram recolhidas, a luminosidade e a organização haviam aumentado. As mulheres da casa pareciam unidas e dispostas ao autocuidado. Discutimos o atual ciclo da vida em que se encontravam, a possibilidade da morte do esposo (provedor de recursos financeiros da família) e o cenário em que se encontravam. A mãe desempregada, as filhas fora da escola por abandono, a falta de documento delas, o abuso de drogas de todas na presença do lactente, o envolvimento da filha mais jovem com pessoas do tráfico de drogas e a filha primogênita trabalhando como profissional do sexo (também testadas para HIV, porém com resultado negativo).

Nesse momento, o auxílio do Núcleo de Apoio à Saúde da Família (NASF) foi essencial, e organizou-se uma planilha de intervenção sistemática para auxiliar toda a equipe a se empenhar no cuidado sistêmico dessa família tão fragilizada (Tabela 1).
Em setembro de 2014 o pai faleceu na Unidade de Terapia Intensiva do HUPE. A possibilidade de sua morte já havia sido discutida e levada em consideração, o que ajudou no processo de luto e continuidade da TARV, além de prevenir recaídas das drogas, tabaco e álcool.

A mãe apresentou resposta ao tratamento de HIV com melhora na contagem de linfócitos T CD4 e queda na carga viral no mês de fevereiro de 2015 (após 4 meses de uso de TARV). A filha mais jovem havia voltado à escola e todas estavam com documentos em ordem.

Em agosto de 2015, as mulheres dessa família sofreram uma violência desse território. Pessoas envolvidas com o tráfico de drogas da comunidade aplicaram um "castigo" na mãe e na filha mais jovem, devido o envolvimento desta filha com um traficante de comunidade rival. Rasparam os seus cabelos, realizando agressões físicas, ameaças de morte com proibição de saírem de casa e de receberem visitas. O cuidado sofreu uma grande agressão.

Apesar de tal proibição em vigor, uma última VD foi realizada para avaliação do estado de mãe e filha, curativos e analgesia, antes que elas fugissem da própria casa, abandonando tudo como fugitivas de um poder paralelo.

A mãe continuou sendo atendida no Ambulatório de Medicina Integral (AMI) do HUPE pelos residentes de MFC, mudou-se para um município vizinho ao Rio de Janeiro e mesmo com todo temor que a obrigou a se refugiar, em setembro de 2015 foi à procura de seu antigo MFC de referência com um sorriso e um papel nas mãos dizendo: "Conseguimos, doutor. O vírus está controlado!" (carga viral indetectável e linfócitos T CD4 > 800).

\section{Discussão}

A incidência de PVHA no Brasil tem apresentado estabilização nos últimos dez anos, com uma média de 20,5 casos para cada 100 mil habitantes. ${ }^{3}$

O Rio de Janeiro também apresentou queda em relação à taxa de incidência dos casos de AIDS: 16,7 por 100 mil habitantes. Chama atenção as altas taxas apresentadas pela área de planejamento (AP) 1.0 - Centro, com uma incidência três vezes maior que a taxa municipal (71,8 por 100 mil habitantes em 2008). ${ }^{4}$

A equipe da APS descrita neste trabalho encontrase na AP 1.0 do Município do Rio de Janeiro, com uma população de alta vulnerabilidade social (5.000 pessoas cadastradas), área de comunidade, com usuários de baixa renda salarial que participam de programas sociais do governo; a violência urbana é pungente, conflitos 
0.us. 33 mos 13varzois Ambulaborito be Medicina integralphapt
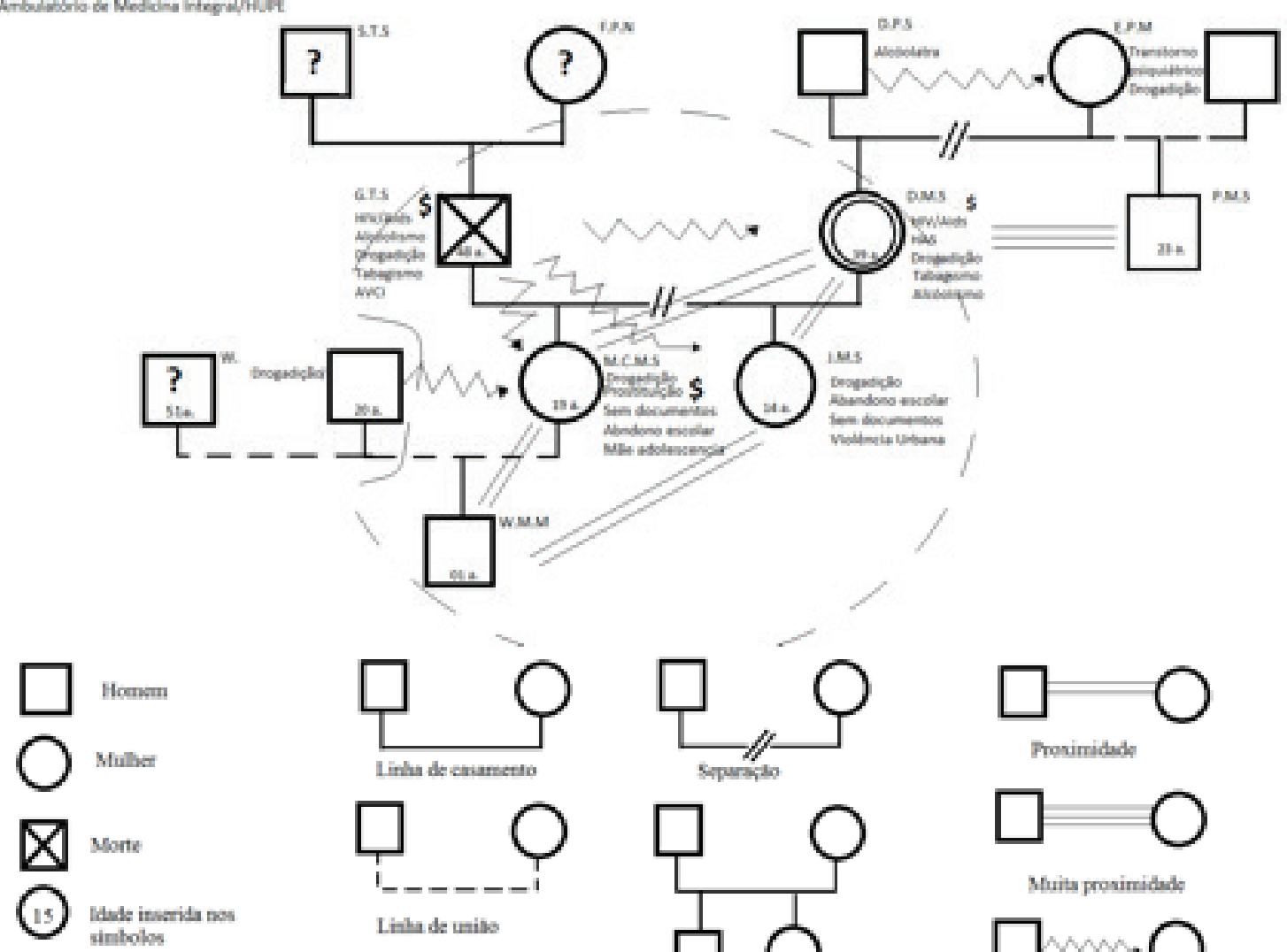

Prosimidade
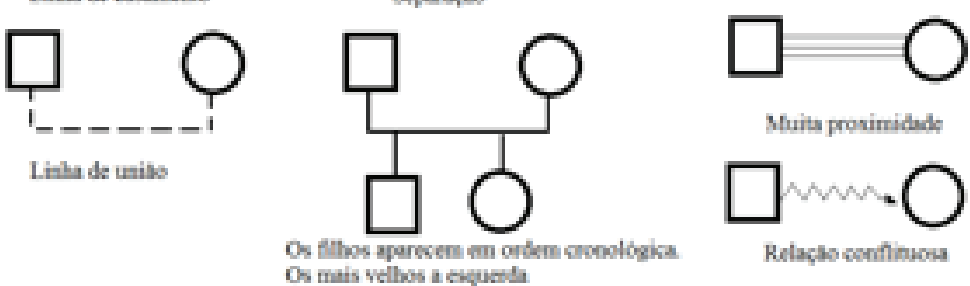

Mfuits prosimidade

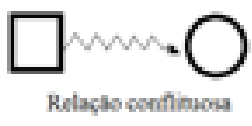

Figura 1. Familiograma e legenda

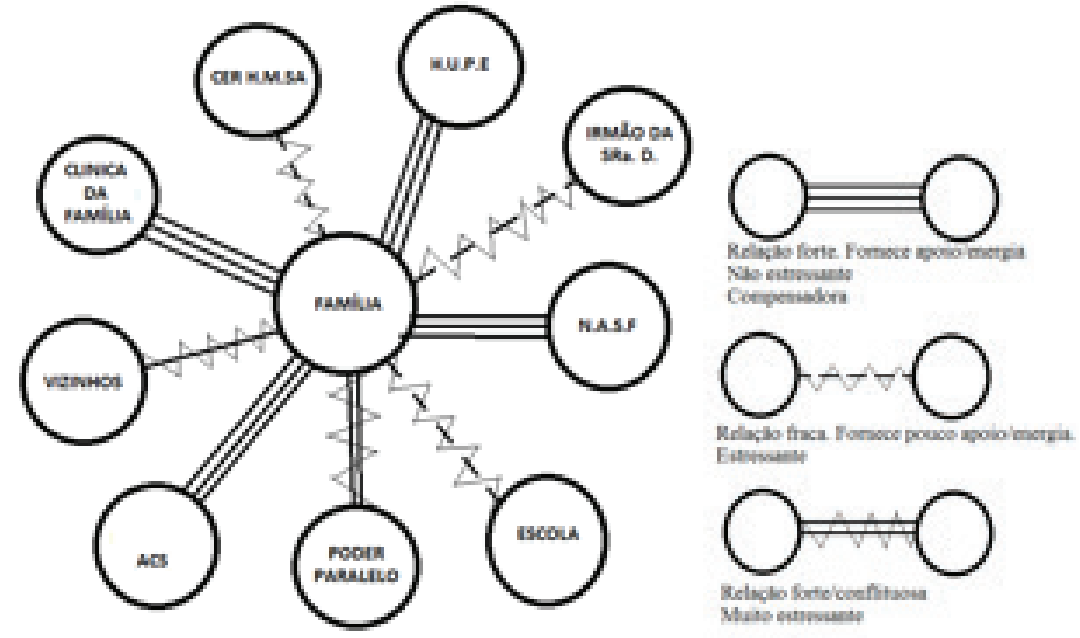

Figura 2. Ecomapa e legenda 


\section{Caso clínico}

Tabela 1. Planilha de intervenção sistemática

\begin{tabular}{|c|c|}
\hline Componente & Análise situacional \\
\hline $\begin{array}{l}\text { Família } \\
\text { Família mononuclear c/pais } \\
\text { separados, mas coabitan- } \\
\text { do juntos. Duas filhas ado- } \\
\text { lescentes, sendo uma mãe. } \\
\text { Apresentam história de vi- } \\
\text { olência sexual, adicção e in- } \\
\text { fecção pelo vírus HIV. }\end{array}$ & $\begin{array}{l}\text { Família passando por } \\
\text { dificuldades financei- } \\
\text { ras após diagnóstico } \\
\text { de HIV dos progeni- } \\
\text { tores; filhas não têm } \\
\text { documentação e aban- } \\
\text { donaram a escola. Pai } \\
\text { internado em CTI com } \\
\text { prognóstico reserva- } \\
\text { do. Mãe encontrando } \\
\text { dificuldades emocio- } \\
\text { nais para lidar com a } \\
\text { situação. }\end{array}$ \\
\hline
\end{tabular}

\begin{abstract}
Pai, 48 anos
Internado em CTI, caso de AIDS, adicto, relação de violência sexual com esposa (situação e breve descrição da pessoa, suas relações afetivas intrafamiliares, problemas de saúde, aspectos relevantes).
\end{abstract}

\section{Mãe, 39 anos}

Caso de AIDS, adicta, s/trabalho, c/histórico de transtornos mentais, sofria abusos do ex-marido.

Primogênita, 19 anos Mãe adolescente e adicta.

Neto, 1 ano

Características do domicílio Casa em péssimo estado de conservação (teto c/buracos, único foco de luz elétrica), presença de animal doméstico (forte cheiro de fezes e urina)..

Filha mais jovem, 14 anos Abandono escolar e adicta.
Diagnóstico recente de HIV/AIDS. Encontra-se internado em CTI c/ prognóstico reservado, sofreu $\mathrm{AVCl}$ e encontra-se $c / h e m i p l e g i a$ D. Sem grandes perspectivas de uma vida funcional.

Diagnóstico de HIV/ AIDS. Encontra-se desempregada, vem abusando do uso de maconha, cocaína e álcool. Encontra-se em estado de choque com a situação do marido e teme o mesmo fim dele.

Adolescente vem usando maconha, abandonou escola, relaciona-se com homem mais velho que lhe dá dinheiro.

Adolescente, vem usando maconha, abandonou o ambiente escolar, não apresenta perspectivas.

\begin{tabular}{lll}
$\begin{array}{c}\text { Seleção dos proble- } \\
\text { mas/priorização }\end{array}$ & \multicolumn{1}{c}{ Metas } & \multicolumn{1}{c}{ Responsável } \\
& $\begin{array}{l}\text { Benefício/INSS/ } \\
\text { Bolsa-Família. } \\
\text { Documentação (CT, }\end{array}$ & $\begin{array}{l}\text { ACS } \\
\text { Assistente social/NASF } \\
\text { RG, CPF). }\end{array}$ \\
& $\begin{array}{l}\text { Conselho Tutelar } \\
\text { Creche/escola. } \\
\text { Acompanhamento bi- }\end{array}$ & Enfermagem \\
\end{tabular}

Acompanhamento biopsicossocial.

\begin{tabular}{|c|c|c|}
\hline $\begin{array}{l}\text { HIV/AIDS. } \\
\text { Tabagismo. } \\
\text { AVCI hemiplegia. } \\
\text { Drogadição. }\end{array}$ & $\begin{array}{l}\text { Realizar exames p/HIV/ } \\
\text { AIDS. } \\
\text { Iniciar TARV. } \\
\text { Acompanhar inter- } \\
\text { nação junto ao HUPE. }\end{array}$ & Médico \\
\hline $\begin{array}{l}\text { HIV/AIDS. } \\
\text { Tabagismo. } \\
\text { HAS. } \\
\text { Drogadição. } \\
\text { Desemprego. }\end{array}$ & $\begin{array}{l}\text { Realizar exames p/HIV/ } \\
\text { AIDS. } \\
\text { Iniciar TARV. } \\
\text { Diminuir danos. } \\
\text { Acompanhamento psi- } \\
\text { cológico. } \\
\text { Coleta de exame cito- } \\
\text { patológico. } \\
\text { Benefício de prestação } \\
\text { continuada. }\end{array}$ & $\begin{array}{l}\text { Médico } \\
\text { Enfermagem } \\
\text { Psicólogo/NASF }\end{array}$ \\
\hline
\end{tabular}

\section{Drogadição.}

Abuso/violência.

Faltam documentos.

Abandono escolar.

Realizar sorologia $\mathrm{p} /$ HIV.

Médico Enfermagem

Acompanhamento psicológico.

Assistente social/ psicólogo/NASF

Falta de documentos.

Abandono escolar

Realizar sorologia $\mathrm{p} /$ HIV.

Médico

Enfermagem

Acompanhamentopsi- Assistente social/ cológico.

\begin{tabular}{l|l|l|l}
$\begin{array}{l}\text { Baixo peso, problema } \\
\text { respiratório. }\end{array}$ & $\begin{array}{l}\text { Consulta médica. } \\
\text { Creche. }\end{array}$ & $\begin{array}{l}\text { Médico } \\
\text { Enfermagem } \\
\text { Assistente social/NASF }\end{array}$ \\
\hline $\begin{array}{lll}\text { Má conservação. } \\
\text { Má higiene local. }\end{array}$ & $\begin{array}{l}\text { Orientações de higiene } \\
\text { do lar. }\end{array}$ & $\begin{array}{l}\text { ACS } \\
\text { Organização do lar } \\
\text { para se tornar ambi- } \\
\text { ente mais salubre. }\end{array}$ \\
& Assistente social/NASF \\
\end{tabular}


armados entre o poder paralelo (facções criminosas rivais) e confronto direto com a polícia; o território não conta com planejamento urbanístico, é constituído por áreas de difícil acesso e foi assumido pelo PRMFC no ano de 2014. No primeiro ano de residência médica (março/2014-março/2015), foram realizados sete diagnósticos de PVHA; seguindo a epidemiologia do município e da AP 1.0 (maior taxa de incidência que a média municipal), o território estudado apresentou 8,4 vezes mais diagnósticos esperados que o município e 1,94 vezes mais diagnósticos esperados que a AP 1.0. ${ }^{5}$

Atualmente, a equipe tem 15 PVHA, oito homens e sete mulheres, mantendo uma relação de 1,14 (a do município é de 1,9 entre homens e mulheres) e uma idade média de 43,6 anos (o maior percentual de casos no município se apresentou entre 20 a 49 anos em ambos os sexos).

Para a estratégia do enfrentamento da epidemia, é necessário conhecer áreas adscritas e buscar o cuidado integral de uma pessoa, considerando seu contexto familiar e comunitário, suas relações interpessoais e de trabalho. A estratégia de saúde que preenche todos os requisitos descritos é a medicina de família e comunidade. ${ }^{6}$

A medicina centrada na pessoa (entender a doença e a experiência da doença, entender a pessoa como um todo, elaborar um plano terapêutico conjunto, prevenção e promoção à saúde, intensificar relacionamento médico-paciente e ser realista) ${ }^{7}$ foi extremamente importante para a abordagem do caso e procurou explorar a doença e a experiência da doença da própria pessoa. A adesão terapêutica para portadores da Síndrome da Imunodeficiência Adquirida (SIDA/AIDS) necessita ser abordada em uma perspectiva multifatorial e singular que considere aspectos socioculturais, significados construídos e autonomia dos indivíduos. ${ }^{8}$

O familiograma é uma ferramenta potente para investigar histórias de doenças e relacionamentos e sobre como padrões passados influenciam o presente. ${ }^{9}$

O ecomapa é outro instrumento de avaliação familiar, uma representação gráfica que identifica todos os sistemas envolvidos e relacionados com a pessoa, com a família em questão e o meio em que vivem..$^{10}$

As VDs realizadas com um intervalo curto (a cada 15 dias) auxiliaram a acompanhar o desenrolar da saúde dessas pessoas e a incentivá-las em seus planos terapêuticos em busca do sucesso de seu tratamento.

\section{Conclusão}

A experiência com as PVHA acompanhadas pela equipe de residência aqui citada ao longo dos dois anos ainda é um número pequeno em uma variável de tempo curta, porém a adesão terapêutica dos mesmos e a melhora clínica do início do tratamento aos dias atuais (seja em ganho ponderal, aumento da autoestima, seja na redução de danos, redução de carga viral e aumento de linfócitos TCD4) é um forte indicador de que esses pacientes podem ter seus cuidados coordenados pelo médico de família e comunidade, sem prejuízo à sua privacidade e podendo ser tratados em seu próprio território se assim desejarem.

\section{Referências}

1. Ministério da Saúde. Portaria n².488, de 21 de out de 2011. Aprova a Política Nacional de Atenção Básica, estabelecendo a revisão de diretrizes e normas para a organização da Atenção Básica, para a Estratégia Saúde da Família (ESF) e o Programa de Agentes Comunitários de Saúde (PACS) [Internet] 2011 [acesso 2017 Fev 23]. Disponível em: http://bvsms.saude.gov. br/bvs/saudelegis/gm/2011/prt2488_21_10_2011.html

2. Favoreto $\mathrm{CAO}$, Camargo Jr KR. Narrative as a tool for the development of clinical practice. Interface comun. saúde educ. [Internet] 2011 [citado 2017 Fev 23] 15(37): 473-483. Disponível em: http://dx.doi.org/10.1590/S1414-32832011005000005

3. Ministério da Saúde (BR), Departamento de DST, AIDS e Hepatites Virais. Boletim Epidemiológico HIV/Aids. [Intenet] 2014 [citado 2017 fev 22] 3(1). Disponível em: http://www.aids.gov. br/publicacao/2014/boletim-epidemiologico-aids-e-dst-2014

4. Secretaria Municipal de Saúde do Rio de Janeiro (BR). Boletim epidemiológico DST/AIDS - SMS-RJ/SUBPAV/SAP [Internet]. 2013 [citado 2017 Fev 22]. Disponível em: http://www.rio.rj.gov. br/dlstatic/10112/4502878/4114721/anexo1_boletim.indd.pdf

5. Prontuário eletrônico do paciente. Consulta (Medicine One). 2017

6. Santos AFM, Deveza M. A AIDS como condição crônica e o papel do Médico de Família e Comunidade e da Estratégia Saúde da Família. Rev. bras. med. fam. comunidade. [Internet] 2012: [citado 2017 Fev 22] 7(22): 10-12. Disponível em: http:// dx.doi.org/10.5712/rbmfc7(22)172

7. Stewart M. Brown JB, Weston WW, et al. Medicina centrada na pessoa: transformando o método clínico. 2 ed. Porto Alegre: Artmed: 2010.

8. Ferreira DC; Favoreto CAO. A análise da narrativa dos pacientes com HIV na construção da adesão terapêutica. Physis (Rio J.). [Internet] 2011; [citado 2017 Fev 22] 21(3): 917-936. Disponível em: http://www.redalyc.org/ html/4008/400838234009/

9. Eia A, Tomson D, Young V, et al. Dez minutos para família: intervenções sistêmicas em Atenção Primária à Saúde. Souza, PM, tradutor. Porto Alegre: Artmed; 2012.

10. Gusso G., Lopes JMC, organizadores. Tratado de Medicina de Família e Comunidade: princípios, formação e prática. Volume1. Porto Alegre: Artmed; 2012. 